rakterisiert. Die Politik des GATT, dessen Ziel einer weitestgehenden Liberalisierung des Handels, nicht zuletzt durch konsequente Anwendung des Prinzips der Meistbegünstigung zugunsten aller GATT-Mitglieder, bloßes Programm geblieben ist, habe UNCTAD geboren, deren Politik es sei, auf der Grundlage neuer Prinzipien den internationalen Handelsaustausch zum gegenseitigen Vorteil aller Staaten zu fördern und zu koordinieren. Die Rohstoff-Frage stehe deshalb seit UNCTAD I (Genf 1964) auf der Tagesordnung aller UNCTAD-Tagungen und habe den Verlauf des Nord-Süd-Dialogs entscheidend beeinflußt. Darin wird man Elian voll zustimmen können. Die Einrichtung eines Internationalen Rohstoff-Fonds, über den sich die Staaten nach vierjähriger Diskussion Ende Juni dieses Jahres in Genf nunmehr geeinigt haben, wäre ohne das betonte Eintreten von UNCTAD für eine Korrektur der traditionellen Prinzipien des internationalen Rohstoff-Handels nicht denkbar gewesen.

Ist der Ansatz Elians auch richtig, daß die ungelösten Fragen des internationalen Wirtschaftsaustausches am wirksamsten durch Zusammenarbeit gelöst werden können, so bleibt doch die weitere Frage unbefriedigend beantwortet, ob denn die Konfliktlösung über juristische Kriterien auch in der Regel erfolgreich ist. Die Praxis der Staaten scheint eher dagegen zu sprechen. Die Debatten der UNO, vor allem in der Generalversammlung, aber auch im Wirtschafts- und Sozialrat und in den entsprechenden UN-Sonderorganisationen, und die dort initiierte Resolutionspraxis weisen das Recht mehr instrumental aus, als Hebel für die Entwicklung zukunftweisender und programmatischer Prinzipien und weniger als Handlungsanweisung angesichts konkreter Interessenkonflikte. Eher könnte man sagen, daß das Recht, sei es als traditionelle Lex lata gegenüber der rechtspolitischen Forderung, sei es als weiterentwickeltes Völkerrechtsprinzip (Gewohnheitsrecht oder ständige Vertragspraxis) verstanden, erst den Interessengegensatz sichtbar macht. Die Einigung, ein prinzipiell politischer Vorgang, erfolgt dann regelmäßig außerhalb des Rechts.

Hermann Weber

B. SEN

\title{
A Diplomat's Handbook of International Law and Practice
}

Martinus Nijhoff Publishers, Den Haag, Boston, London, 2. Auflage, 1979, XXXIII, 529 S.

Der Generalsekretär des Asian-African Legal Consultative Committee und frühere Rechtsberater des indischen Außenministers legt sein Handbuch, das erstmals 1963 erschien, nunmehr in überarbeiteter und erweiterter Fassung vor. In seiner Ausrichtung auf die Bedürfnisse der Gestaltung des praktischen Völkerrechtsverkehrs, auf Probleme des Diplomatenund Konsularrechts insbesondere, ähnelt das Buch Satow's Guide to Diplomatic Practice, der gleichfalls 1979 in neuer Auflage erschienen ist ${ }^{1}$. Der Bereich der internationalen Organisationen ist allerdings bei Sen nach wie vor ausgeklammert. Die Neuauflage weist Änderungen vor allem im Bereich des Vertragsrechts auf - Konsequenz des Abschlusses der Wiener Vertragsrechtskonvention. Sonstige Entwicklungen der 60er und 70er Jahre hat der Autor in einem Schlußkapitel (S. 468-480), dessen Gliederung der Untergliederung des Gesamtbandes folgt, zusammenzufassen versucht. Obwohl also keine geschlossene Darstellung des geltenden Rechtszustandes gegeben wird, lohnt sich der Blick in Sen's Handbuch bei der Suche nach Staatenpraxis nicht nur bezüglich der schon erwähnten Rechtsgebiete, sondern vor al-

1 Vgl. die Rezension in VRU 12 (1979), S. 274 f. 
lem auch in den Bereichen Anerkennung, Asyl, mit Einschränkungen auch Wirtschaftsvölkerrecht. Rechtsauffassungen der afro-asiatischen Staaten werden überdurchschnittlich häufig erwähnt.

Philip Kunig

\section{DeREK W. BOWETT}

\section{The Legal Regime of Islands in International Law}

Oceana Publications, Inc., Sijthoff \& Noordhoff, New York und Alphen aan den Rijn, 1979, 337 S.

Im ersten Teil des Buches geht es um allgemeine Rechtsfragen betreffend die Rechtsstellung von Inseln. Begrifflich sind ,Inseln“ nach der Definition des Genfer Ubereinkommens über das Küstenmeer und die Anschlußzone von 1958 allein ,,natürlich entstandenes Land“. Die sogenannten künstlichen Inseln erfahren eine andere völkerrechtliche Behandlung, deren wichtigste Besonderheit das Fehlen eines eigenen Küstenmeeres ist. Nach seinen Ausführungen zum Inselbegriff kommt Bowett zu territorialen Fragen wie der Abgrenzung zwischen Landgebiet und Küstenmeer bei Schärenküsten (Problem der Basislinien), der territorialen Souveränität über Inseln jeweils in den einzelnen maritimen Territorialzonen (Eigengewässer, Küstenmeer, Hohe See) und in schiffbaren Flüssen. Besondere Berücksichtigung findet die internationale Judikatur, wobei der auch heute noch in einer Vielzahl von Fragen einschlägige Schiedsspruch Max Hubers im Palmas-Fall aus dem Jahre 1928 hervorzuheben ist. Der Rechtslage von Archipelen, von künstlichen Inseln und von Inseln auf dem Kontinentalschelf sind anschließend eigene Kapitel gewidmet, die auch die künftige Rechtslage nach der Dritten Seerechtskonferenz gebührend einbeziehen. Genannt sei hier nur beispielsweise die Regelung über die Eigengewässer von Archipelstaaten.

Dem allgemeinen Teil schließt sich ein besonderer an, in dem vier aktuelle Streitfälle abgehandelt werden. Es sind dies die Abgrenzung auf dem Kontinentalschelf zwischen England und Frankreich im Bereich der Kanalinseln und am Atlantik, zweitens die türkisch-griechischen Differenzen um das Recht zur Nutzung des Ägäischen Meeres, das nach türkischer Ansicht in seinem östlich der Mittellinie gelegenen Teil zum türkischen Kontinentalsockel gehört, drittens die seewärtigen Grenzen der Anliegerstaaten im Chinesischen Meer und schließlich der kolumbianisch-venezuelanische Streit über Schelfgebiete im Golf von Venezuela. Alle Streitfälle sind anders als der vor kurzem beigelegte Streit zwischen Chile und Argentinien um Inseln im Beagle-Kanal noch nicht gelöst. Das Buch ist sorgfältig und in den meisten Teilen auch sehr ausführlich geschrieben. Allerdings muß man es trotz der wichtigen Thematik als eine außerordentlich trockene Fachschrift bezeichnen.

Hans-Heinrich Nöll

R. W. James/F. M. Kassam (Hrsg.)

\section{Law and its Administration in a One Party State}

Selected Speeches of Telford Georges. East African Literature Bureau, Nairobi, Kampala, Dar es Salaam, 1973, 150 S.

Der aus Trinidad und Tobago stammende Richter Telford Georges wurde 1965 zum ersten Chief Justice Tansanias nach dessen Umwandlung in einen Einparteienstaat ernannt. Er übte das höchste Richteramt in diesem Staat sechs Jahre lang aus und erlebte dabei so wichtige politische Weichenstellungen mit wie die Verabschiedung der Arusha Declaration von 1967. Erst als Nachfolger von Georges wurde erstmals ein tansanischer Richter Chief Justice. Ge-: 